\title{
DÜBLIN
}

Technological University Dublin

ARROW@TU Dublin

\section{Community Microgrid Based on Micro-Wind Generation System}

\author{
Lubna Mariam \\ Technological University Dublin \\ Malabika Basu \\ Technological University Dublin, mbasu@tudublin.ie \\ Michael Conlon \\ Technological University Dublin, michael.conlon@tudublin.ie
}

Follow this and additional works at: https://arrow.tudublin.ie/engscheleart

Part of the Electrical and Electronics Commons

\section{Recommended Citation}

Mariam, L.; Basu, M.; Conlon, M.F., "Community Microgrid based on micro-wind generation system," Power Engineering Conference (UPEC), 2013 48th International Universities' , vol., no., pp.1,6, 2-5 Sept. 2013 doi: 10.1109/UPEC.2013.6715017

This Conference Paper is brought to you for free and open access by the School of Electrical and Electronic Engineering at ARROW@TU Dublin. It has been accepted for inclusion in Conference papers by an authorized administrator of ARROW@TU Dublin. For more information, please contact arrow.admin@tudublin.ie, aisling.coyne@tudublin.ie,gerard.connolly@tudublin.ie.

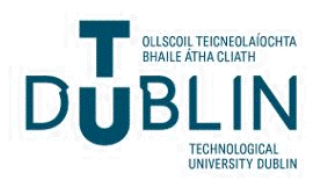




\section{Community Microgrid based on micro-wind generation system}

\author{
Lubna Mariam \\ School of Electrical and Electronic \\ Engineering, Dublin Institute of \\ Technology, Ireland \\ E-mail: lubna.mariam@gmail.com
}

\author{
Malabika Basu \\ School of Electrical and Electronic \\ Engineering, Dublin Institute of \\ Technology, Ireland \\ E-mail:mbasu@ieee.org
}

\author{
Michael F Conlon \\ School of Electrical and Electronic \\ Engineering, Dublin Institute of \\ Technology, Ireland \\ E-mail: Michael.conlon@dit.ie
}

\begin{abstract}
Penetration of renewable energy sources (such as solar/wind) are being explored mostly as micro power generation $(\mu \mathrm{Gen})$ or mega power plant system. In recent years, emphasis has been given on Microgrid ( $\mu$ Grid) systems because of their few advantages over $\mu$ Gen systems in terms of power quality, stability, reliability, economics etc. But the commercial installation of the $\mu$ Grid system is not yet progressing significantly. This paper presents the techno-economic aspects of $\mu$ Gen and $\mu$ Grid systems towards the development of grid connected community based $\mu$ Grid $(C-\mu G$ rid) system. Emphasis has been given to identify the benefits of the $\mu$ Grid over the $\mu$ Gen system. As a case study, wind energy $\mu$ Gen based $C-\mu$ Grid system has been considered. Ireland has been chosen as a geographical location where wind power based $\mu$ Gen system is not yet very popular with present REFIT (Renewable Energy Feed-in-Tariff) policy. To discuss the issues, techno-economic analysis has been performed for both the systems. It shows that if the same REFIT policy is applied for $\mathrm{C}-\mu \mathrm{Grid}$ system, the system could show better performance over the $\mu$ Gen system in terms of stability and cost of energy (COE).
\end{abstract}

Index Terms -- Renewable Energy, Micro generation, Microgrid, Community microgrid, Techno-economic Analysis, REFIT policy.

\section{INTRODUCTION}

Microgrid ( $\mu \mathrm{Grid}$ ) gives the concept of single organized power subsystem associated in a LV distribution network with few micro-generators, both renewable and/or conventional, a cluster of loads and some storage devices [1$3]$. Moreover, the concept of $\mu \mathrm{Grid}$ has been identified as an easy way to integrate the micro-generators to the LV networks [3-4]. Micro generation systems are already being popular for last few years as distributed generators in LV networks. $\mu$ Grid systems are still in the test bed [5] condition though it has several advantages over $\mu$ Gen system. The proposal of community based grid connected $\mu$ Grid is a system where the local people of a community can develop a $\mu$ Grid system by integrating their existing/newly purchased $\mu$ Gen systems. The proposed system has some advantages both technically and economically over the $\mu \mathrm{Gen}$ system. According to O'Rourke [6], among the European countries, wind energy resource is four times larger in Ireland. This exceptional advantage has made Ireland a potential region for electricity generation from wind energy. Electricity generation from wind resource in Ireland has exceeded 1600 MW in total installed by 2011 [7]. Although large scale wind- electricity generation is quite popular, micro wind-electricity generation has not yet very potential in Ireland [8]. In this paper section II shows the present $\mu$ Gen scenario in Ireland where micro-wind based $\mu$ Gen is not yet popular even with the positive support from the Government in their REFIT policy. Advantages of $\mu$ Grid over the $\mu$ Gen systems are described briefly in section III. The idea of the development of community based grid connected $\mu$ Grid system has been proposed in section IV. Section V deals with the details of techno-economic analysis for both of the systems in Irish condition. Results and discussion are to be found in section VI followed by conclusion in section VII.

\section{SCENARIO OF MICRO WIND GENERATION SYSTEM IN IRELAND}

In Ireland a large number of dispersed population lives in remote and isolated rural areas and the network per customers are over four times the European average per capita [6]. Government is encouraging to introduce $\mu$ Gen system among the end level consumers as a better solution to reduce the network losses and at the same time saving the overall cost of energy. In Ireland, $\mu$ Gen is classified as a grid connected electricity generation system up to a maximum rating of $11 \mathrm{~kW}$ for $400 \mathrm{~V}$ three phase distribution line. But majority of the domestic and agricultural customers are connected to the single phase distribution line $(230 \mathrm{~V})$ and for them the maximum technical rating permitted is $5.75 \mathrm{~kW}$. These ratings are in line with EN 50438 (Irish conditions). However, Irish electricity network accepts $\mu$ Gen system up to $6 \mathrm{~kW}$ [7]. A report shows that at the end of 2010 in Ireland, nearly $2 \mathrm{MW}$ installed grid connected $\mu$ Gen systems are present and the share in the total energy production is around $1 \%$ [9]. According to this report, micro wind installation capacity in Ireland is $1818.15 \mathrm{~kW}$ where total number of installation is 357. Market share by capacity and installation of micro wind system is $92.6 \%$ and $85.2 \%$ of the total $\mu$ Gen system. Fig. 1 and 2 shows the percentage of renewable energy (RE) resources among total Irish electricity production [7]. According to the REFIT policy in Ireland, $\mu$ Gen users receives $0.09 € / \mathrm{kWh}$ for all exported electricity to the grid, which is much lower than the importing grid electricity cost. Government is also providing a free export/import meter and $0.10 € / \mathrm{kWh}$ for the first $3000 \mathrm{kWh}$ exported electricity as an 
incentive [8]. Despite of these facts, wind energy based $\mu \mathrm{Gen}$ system is not yet economically feasible in Ireland if it is installed in location with low average speed $(<5 \mathrm{~m} / \mathrm{s})$ [8]. On the other hand, though the consumers have high interest to move for green energy as a viable solution, Government has not yet placed any $\mu$ Grid structure in the policy.
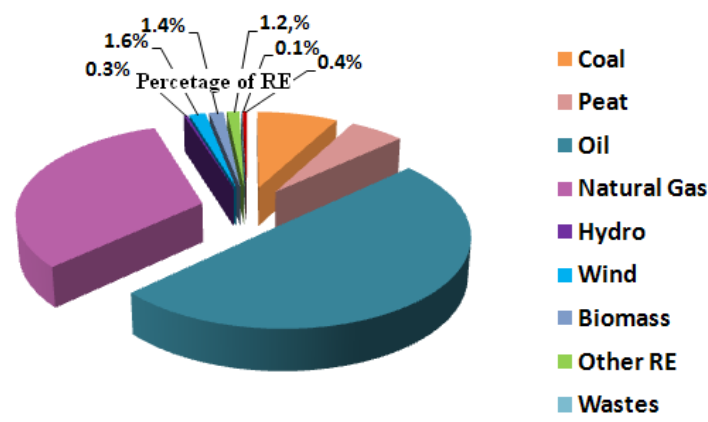

- Imported Electricity

Fig. 1. Share of RE systems in total Irish electricity production.

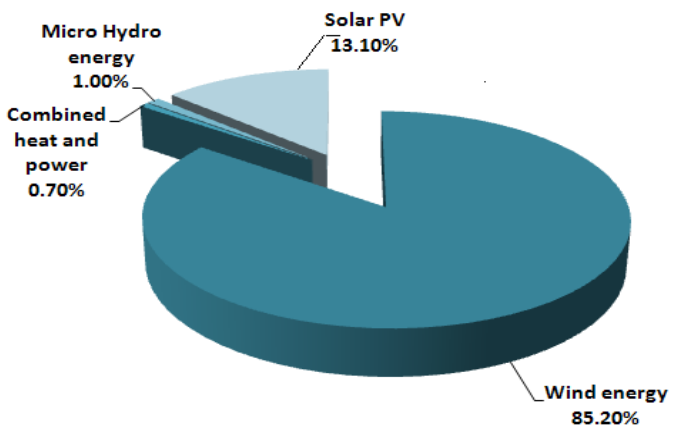

Fig. 2. Share of various kind of RE systems in Irish electricity production

\section{AdVANTAGES OF $\mu$ GRID OVER $\mu$ GEN SYSTEMS}

One of the main intentions of this paper is to consolidate a set of technical and financial reasons to gradually divert from $\mu \mathrm{Gen}$ to $\mu \mathrm{Grid}$ system. Some of the aspects are given below;

\section{A. Technical aspects:}

Due to technical safety and economical reasons, integration of distributed generators (DGs) on power system has been increasing during last decades. Furthermore interface of $\mu \mathrm{Gen}$ systems in LV network has been developed in the last few years [3]. Application of DGs in a large scale is facing some complex challenges as the existing distribution system is not capable of handling multi directional power flow and large number of micro-generators. As a result different kind of technical problems associated with protection and control system arise [4]. High penetration of micro converters connected to the low voltage distribution line could create voltage disturbances and unbalances in the main grid, thus the power quality can decrease. On the other hand in a $\mu \mathrm{G}$ system, cluster of micro-generators, storage system and controllable loads can be integrated by active network management and multi-directional power flow is also possible [10]. $\mu \mathrm{G}$ provides the facility of further deployment of more DGs in the system and highly efficient power plants such as Combined Heat and Power (CHP). It can increase the reliability of power flow to highly sophisticated customers by improving the voltage quality in $\mu \mathrm{G}$ system through the appropriate control of DG converters [11]. One of the main advantages of $\mu \mathrm{G}$ system is that when there is power disturbance in the line it can operate in islanding/autonomous mode and can minimize the interruption of the electricity supply [4].

\section{B. Economic aspects:}

$\mu \mathrm{Gen}$ systems are economically remunerated with special tariff in most of the countries which is absent in most cases for $\mu \mathrm{G}$ system. If the same tariff/REFIT policy is applied in $\mu \mathrm{G}$ system, the system could show better results [10] and thus it can be commercially popularized. Number of barriers that the $\mu$ Gen systems facing are (i) relatively low electricity price which discourages investors, (ii) relatively high capital cost, (iii) insufficient market support mechanism, (iv) lack of incentives which limits the number of DGs that can be connected to the network [4]. On the contrary, due to the less components and larger inverter size the investment cost can be reduced and thus the production cost of energy (COE) can be lower in $\mu \mathrm{G}$ systems. Furthermore, financial benefits for GHG reduction in the REFIT policy can also help the $\mu \mathrm{G}$ system to be economically viable.

\section{Environmental aspects:}

If $\mu \mathrm{G}$ system consists of more renewable energy sources (RES), the pollution level can be very low. Compared to the conventional power generation system, RES based $\mu \mathrm{G}$ system reduces the GHG emission and thus can improve the environment [12]. GHG reduction is also remunerated with the government energy policy. Though RE sources are not controllable, inclusion of storage systems and the ability to control of its internal load could make the $\mu \mathrm{G}$ system Smart and also environment friendly.

\section{Social aspect:}

Planning a sustainable 'Green Energy System' based on local community can build civic awareness between the homeowners. The people in the community would believe that environment friendly projects, sustainable building management and good home maintenance practice through active load management system can enhance the quality of their life and of their neighbours. The school children could be taught about the whole system so they will be aware about system. When the community users have a clear concept of the $\mathrm{C}-\mu \mathrm{G}$ system then can be more conscious about the design, site development, preserving the surrounding ecological system by choosing green space, restoring wetland, groundwater recharge zone and avoid building the developments beside water resources.

\section{PROPOSED COMMUNITY $\mu$ GRID (C- $\mu$ GRID) SYSTEM}

In the $\mu$ Grid structure, the power sources could be closer to the consumer's point that would reduce the transmission loss 
and the impact of individual failures could be reduced [13]. In the proposed $\mathrm{C}-\mu \mathrm{Grid}$ system, few neighbourhoods in an area intend to form an integrated energy system with their own $\mu \mathrm{Gen}$ systems (specially renewable energy sources) for a safe, reliable, energy efficient, cost-effective and dependable power system. The system can also save capital and investment cost over individual generator owners. The $\mathrm{C}-\mu \mathrm{G}$ system consists of a common generation facility, protection, control and monitoring system to meet the interconnection requirements [14]. For making a significant impact on national power system, the $\mathrm{C}-\mu \mathrm{Grid}$ would be able to generate sufficient energy to serve the community and larger geographical footprint as well [15]. This is to support islanding condition when power outage occurs in the grid line. In the event of power outage homeowners automatically experiences a smooth and safe transition to the emergency backup. The system can eliminate stress associated to the power interruption. For developing a successful $\mathrm{C}-\mu \mathrm{Grid}$ the following points must be considered: site development, cluster development, greenways, minimum disturbance, wildlife reservation, woodland conservation etc. Some important features of $\mathrm{C}-\mu \mathrm{Grid}$ system are as follow [15]:

Advantages:

1) The community residents do not have to buy a personal emergency generator.

2) Maintenance could be done professionally and the cost could be shared.

3) There is no requirement for storage at each house separately as $\mathrm{C}-\mu \mathrm{Grid}$ can have a central storage system.

4) The $\mathrm{C}-\mu \mathrm{Grid}$ can minimize environmental impact.

5) This $\mu$ Grid enables the utility to restore their power safely at a lower priority.

6) Through the utility control and monitoring system the utility could be able to monitor remotely the condition of the system.

7) Benefits can also include lower operating cost for residents, increased comfort and higher perceived value.

Disadvantages:

1) $\mathrm{C}-\mu \mathrm{Grid}$ concept has some restriction regarding technical, legal and regulatory issues that requires collaboration between the developer, homeowner and the electric utility.

Fig. 3(a) shows an electrical network consisting of grid connected multiple $\mu$ Gen systems and Fig. 3(b) shows the proposed $\mathrm{C}-\mu \mathrm{Grid}$ system. In $\mu \mathrm{Gen}$ systems, generally micro wind turbines are placed at the front or beside the local house and connected to the load and grid through a micro grid-tie converter. In $\mathrm{C}-\mu \mathrm{Grid}$ system, a number of $\mu \mathrm{Gen}$ systems are connected together to form a separate grid structure with a central $\mu \mathrm{Grid}$ converter. In the proposed $\mathrm{C}-\mu \mathrm{G}$ system, each of the community users will use their own micro wind turbine (as $\mu \mathrm{Gen}$ ) and instead of having separated multiple converters, all the wind turbines of the users will be connected through a central converter. Rest of the structure of the $\mu \mathrm{Gen}$ and $\mathrm{C}-\mu \mathrm{Grid}$ will remain the same. The technological advantages of the proposed system are (i) due to less number of power electronics converters, the system could be technically stable by reducing the $\mathrm{AC}$ current circulating path, (ii) power quality could be improved by reducing the possibility of voltage unbalance condition. The financial aspect of the proposed system is that, as converter size increases its cost reduces (as shown in Fig. 4) so it could reduce the investment cost and therefore system could be economically viable. The other issue of this proposal is that it may be beneficial for the end users of the country where $\mu$ Grid policy is not yet available in the REFIT policy like Ireland. Under the REFIT policy for $\mu \mathrm{Gen}$ in Ireland, the end user can connect their $\mu$ Gen system to the low voltage distribution network but still it is not economically a viable option. In that case, the user can explore the $\mathrm{C}-\mu \mathrm{Grid}$ idea under the $\mu$ Gen policy to gain the techno-economical advantages.

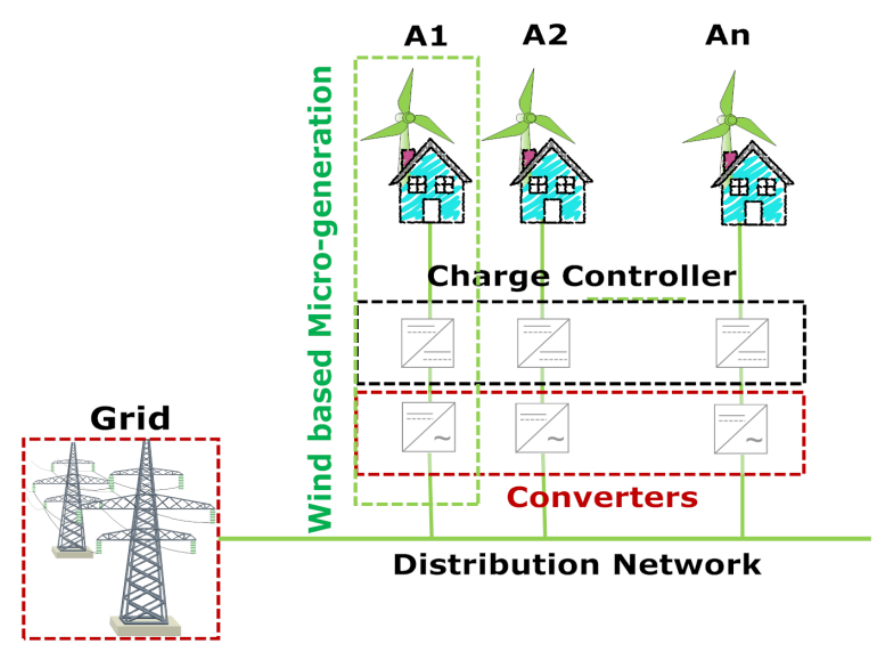

Fig. 3(a). Micro generation system $(\mu \mathrm{Gen})$

Community based Microgrid System

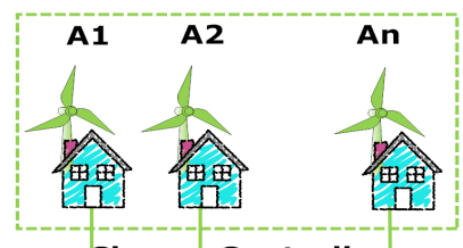

Charge Controller

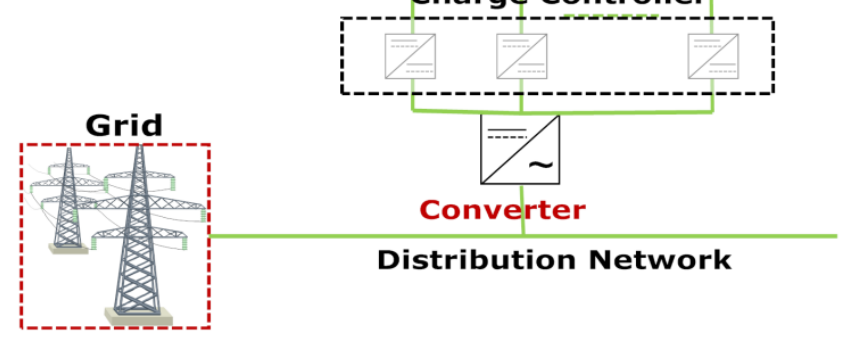

Fig. 3(b). Proposed Community based micro grid system (C- $\mu$ Grid) 


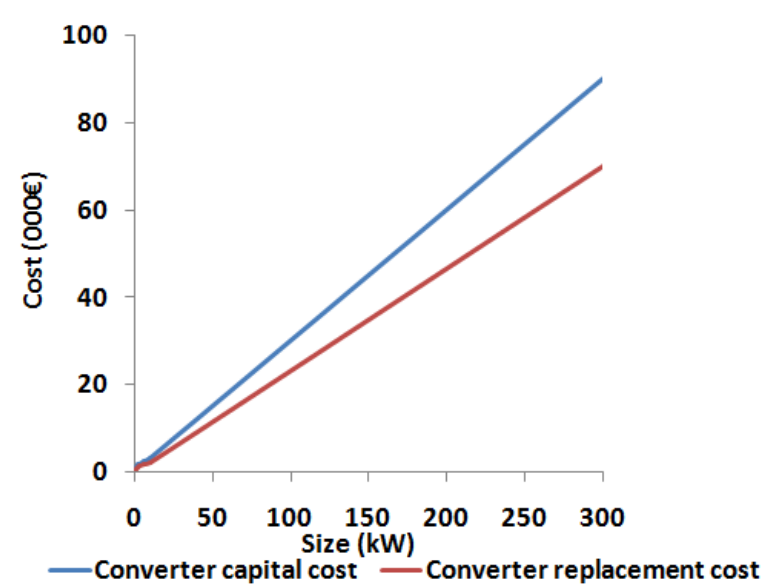

Fig. 4. Capital and replacement cost of converter for different sizes

\section{TECHNO-ECONOMICAL ANALYSIS}

To implement the proposed $\mathrm{C}-\mu \mathrm{Grid}$ system, one set of community area in Dublin, Ireland consisting of 50 houses has been virtually considered. It has been assumed that each of the 50 houses have their own wind energy based $\mu \mathrm{Gen}$ systems. In $\mu$ Gen system, each consumer has one charge controller (CC) and a micro converter in their own system, as shown in Fig. 3(a). While they are considered in the $\mathrm{C}-\mu \mathrm{Grid}$ system as shown in fig. 3(b), their micro wind turbines are connected together through their own CC to a total capacity single unit converter. The other advantage is that in $\mu \mathrm{Gen}$ system, each consumer needs their own export/import meter whereas in $\mathrm{C}-\mu \mathrm{Grid}$ system, only one meter is enough to measure the exported energy from the $\mu \mathrm{Grid}$ to the distribution line. One of the important criteria is that the consumers of the community would agree to share the investment and benefits of the system equally. Both the systems have been designed and simulated partly in HOMER, one of the most popular micro power optimization software [16]. Rest of calculation is done manually in Microsoft Excel. Wind speed data has been collected from MET Éireann [17] and load demand for a general household in Dublin have been collected from the respective authorities [18].

A green loan of $4.5 \%$ rate from St Patrick's Credit Union in Ireland is considered. All calculations are based on this loan rate unless it is stated differently. An annual inflation rate of $2.26 \%$ is taken which was the average annual inflation rate for Ireland between January 2001 and December 2010 [19]. Grid electricity bill for day time ( 0.233 euro cent) and night time ( 0.153 euro cent) are taken from the local authority of electricity, ESB [20].

\section{RESULT AND DISCUSSION}

To understand the technical performance (in terms of energy export/import), monthly average hourly data has been extracted from the simulation study. Load demand, generated wind power, import from grid (grid purchases) and export to grid (grid sales) data for both of the systems have been collected. Fig. 5 shows the performance for both of the systems for the four months over the year (January, April, July and October) where $5(\mathrm{a}, \mathrm{c}, \mathrm{e}, \mathrm{g})$ and $5(\mathrm{~b}, \mathrm{~d}, \mathrm{f}, \mathrm{h})$ represent the analysis for $\mu \mathrm{Gen}$ and $\mathrm{C}-\mu \mathrm{Grid}$ respectively. For both the cases, it is found that the load profile from the evening to morning time almost follow the wind power profile. Though the average wind power availability during this time period is much higher then the load demand, still the user purchases energy from the grid. It happens due the mismatch of the profile for some typical days over the month. Also the wind power is higher in the winter months (October, January).

Another finding is that, wind penetration is very high during the noon time when load demand is low. Therefore, most of wind power is transferred to the grid. At peak load hours also the consumer does not have to buy much electricity from the grid, thus can save money.

Integration of storage system in the $\mathrm{C}-\mu$ Grid could be beneficial for the consumers in the way that they could store energy in the low demand hours and then use it in peak load period. It could increase the stability of the system, but at the same time it will increase the cost of the system. This issue is a matter of compromise with the economical sustainability of the system.

Besides the technical analysis, the economic analysis shows that the net grid purchase of energy for a single unit grid connected micro-generator is negative, as shown in Table 1 . It means that a $6 \mathrm{~kW}$ micro wind based $\mu \mathrm{Gen}$ system in Irish condition can produce energy above the one household load demand and supply the extra electricity to the grid. On that regard it can be stated that the more energy production, more supply to the grid. The cost of the energy from a $\mu$ Gen system is shown in Table 2 . Based on the available cost information, the production cost of energy from this $\mu$ Gen system is lower than the grid purchase cost but higher than the grid sale cost mentioned in the REFIT policy. Therefore, wind energy based $\mu$ Gen system may not be feasible for grid sale condition. Rather it would be a better option to introduce storage device in the $\mu$ Gen system to use the excess energy during the peak load demand. Otherwise, Government has to increase the REFIT price in the policy.

The other possible way is to increase the system size and thus can reduce the cost of energy. It will then raise the problem of space availability and the technical rules and regulations from the authority. In Ireland, for grid connected $\mu$ Gen system, the maximum capacity is $6 \mathrm{~kW}$ in single phase and $11 \mathrm{~kW}$ for three phase system.

Therefore, the idea can be shifted from $\mu$ Gen system to a C$\mu$ Grid system where the local community users can integrate their $\mu$ Gen systems and then connected to the grid, as shown in Fig 3(b). In that case instead of connecting the wind turbines with number of micro-converters, a single converter of bigger capacity is used to connect to the grid. As it is stated earlier that the converter cost decreases as its size increases, the initial investment cost can be reduced and thus the COE can also be reduced. 


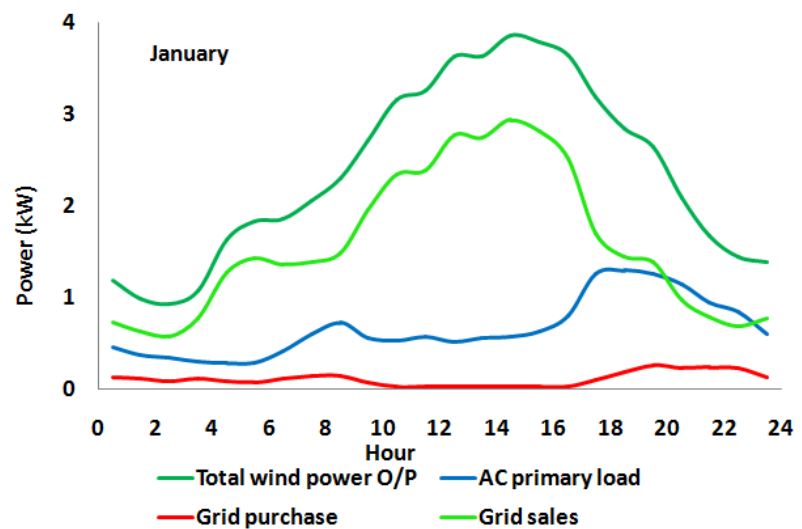

(a)

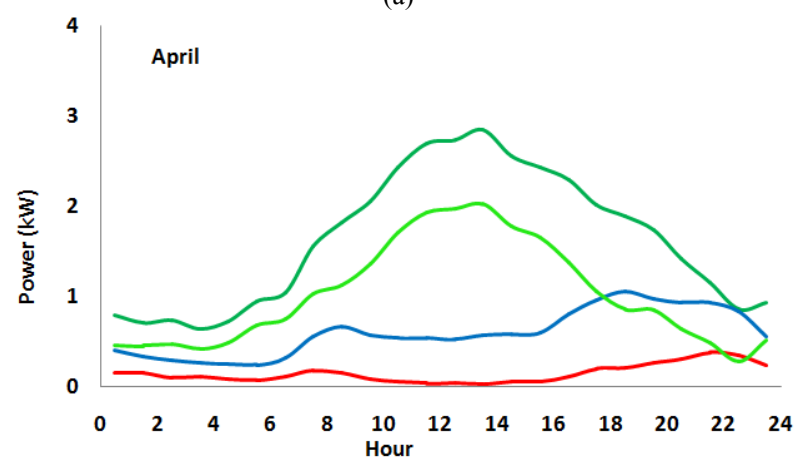

- Total wind power $\mathrm{O} / \mathrm{P}$ - AC primary load

-Grid purchase -Grid sales

(c)

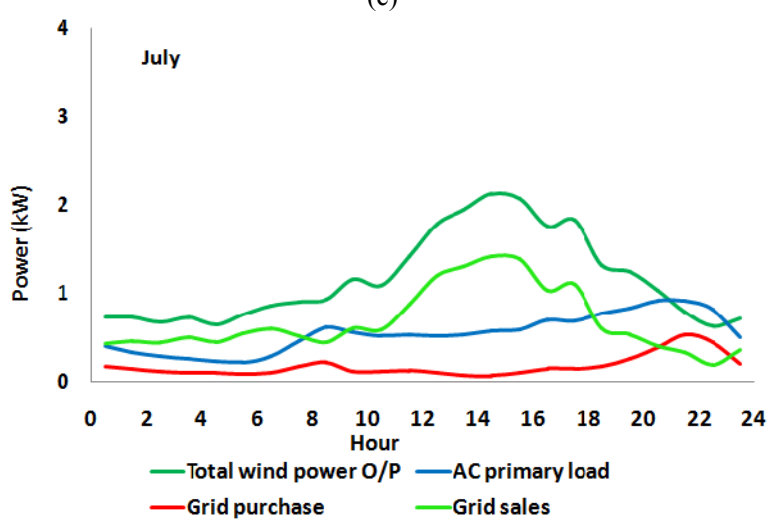

(e)

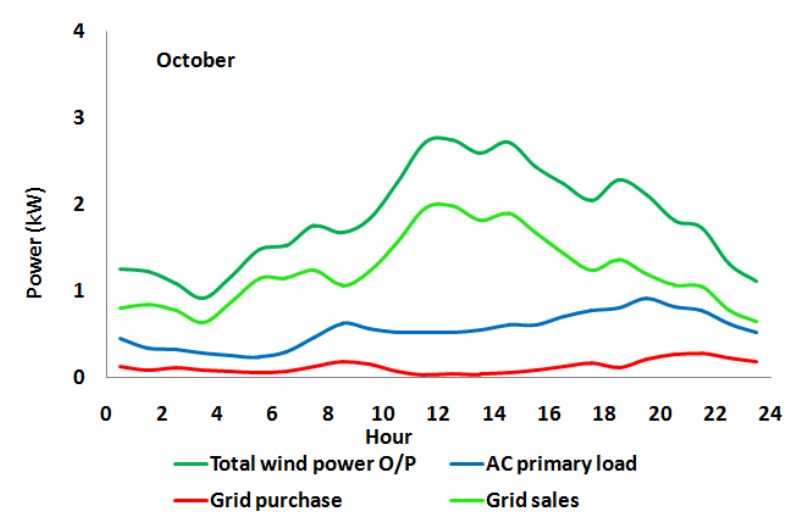

(g)

Fig.5. Technical performance of $\mu \mathrm{Gen}(\mathrm{a}, \mathrm{c}, \mathrm{e}, \mathrm{g})$ and $\mathrm{C}-\mu \mathrm{Grid}(\mathrm{b}, \mathrm{d}, \mathrm{f}, \mathrm{h})$ system

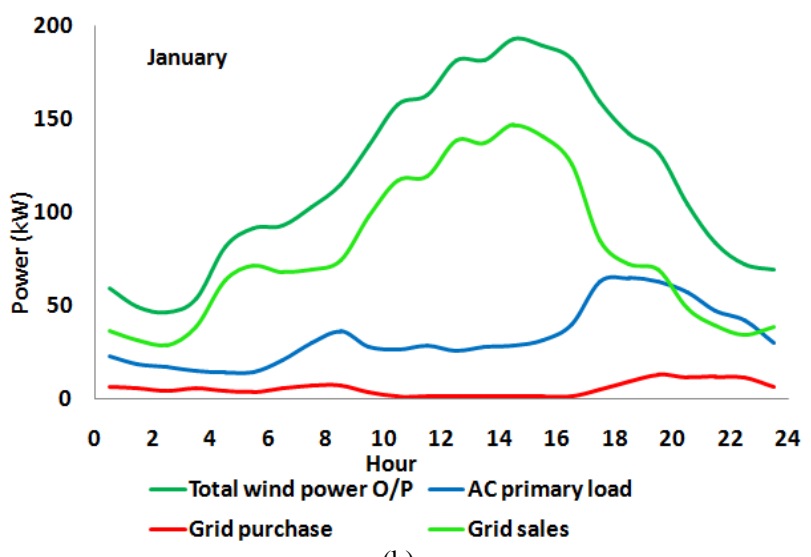

(b)

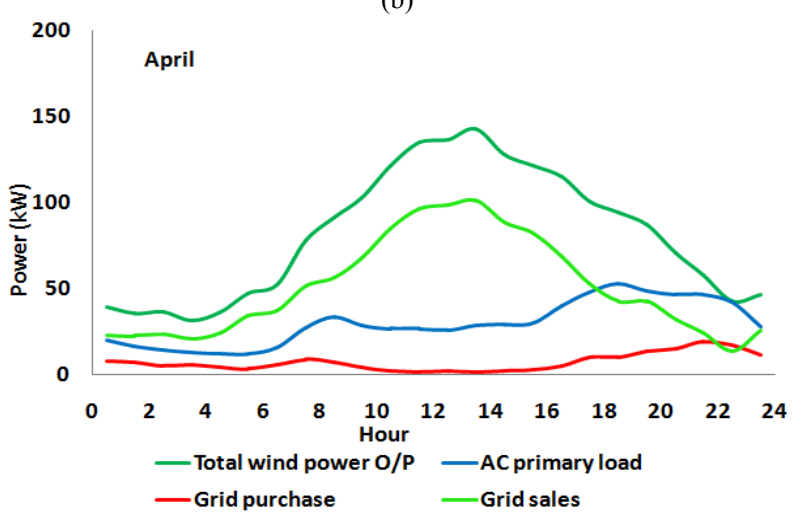

(d)

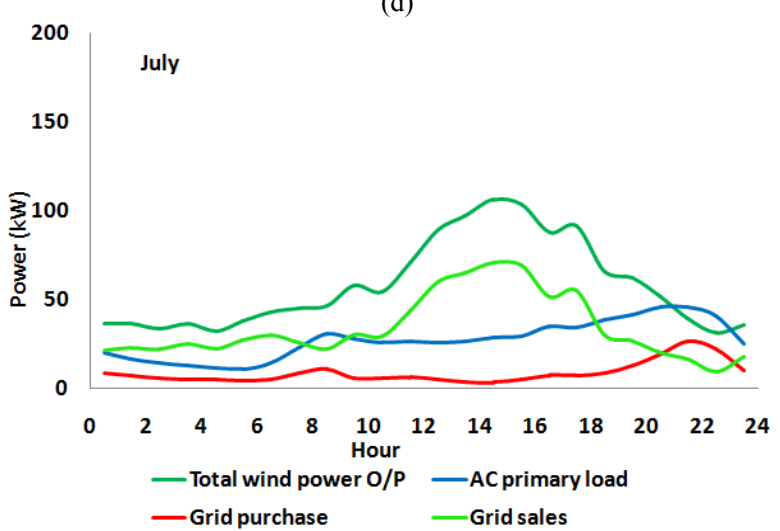

(f)

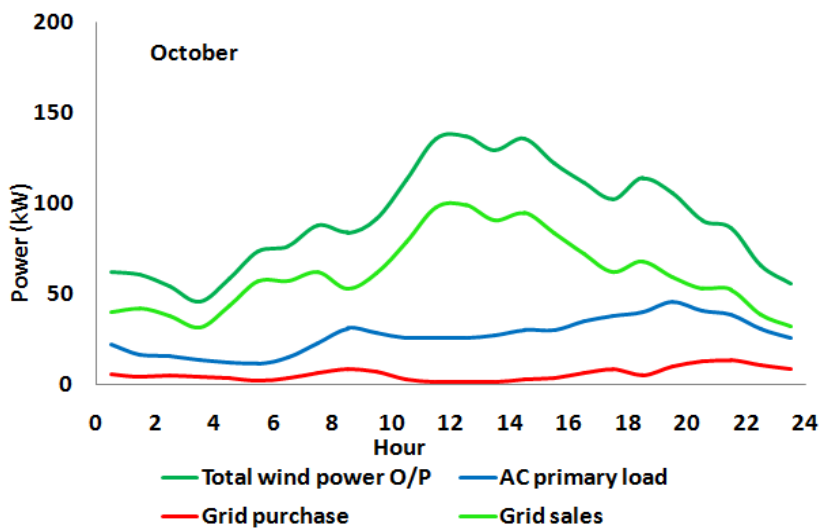

(h) 
Table 2 shows the techno-economical information and $\mathrm{COE}$ of a $\mathrm{C}-\mu \mathrm{Grid}$ system consisting of 50 houses. It is found that the initial investment and total system cost are lower in the $\mathrm{C}-\mu \mathrm{Grid}$ concept compared to $\mu \mathrm{Gen}$ system. Thus the production COE for grid sale becomes lower than the REFIT price in the policy. Therefore the system can become economically viable for the community users. It could also reduce the export/import metering cost for the Government. If the Government then provides the savings of meter cost as an incentive to the community, it could further reduce the overall system cost to become it more sustainable.

TABLE I

ENERGY PURCHASED FROM AND SOLD TO THE GRID FOR 1 HOUSEHOLD LOAD

\begin{tabular}{|l|c|c|c|}
\hline \multirow{2}{*}{ Month } & $\begin{array}{c}\text { Energy } \\
\text { Purchased }\end{array}$ & Energy Sold & Net Purchases \\
\cline { 2 - 4 } & $(\mathrm{kWh})$ & $(\mathrm{kWh})$ & $(\mathrm{kWh})$ \\
\hline Jan & 4216 & 58737 & -54521 \\
\hline Feb & 3918 & 54227 & -50308 \\
\hline Mar & 4929 & 54619 & -49690 \\
\hline Apr & 5290 & 36549 & -31259 \\
\hline May & 6424 & 30247 & -23823 \\
\hline Jun & 6092 & 25890 & -19798 \\
\hline Jul & 6607 & 25255 & -18647 \\
\hline Aug & 6436 & 26802 & -20366 \\
\hline Sep & 5651 & 31722 & -26071 \\
\hline Oct & 4448 & 45601 & -41145 \\
\hline Nov & 4330 & 43652 & -39323 \\
\hline Dec & 62505 & 485335 & -422830 \\
\hline Annual & & 52034 & -47870 \\
\hline
\end{tabular}

TABLE II

TECHNO-ECONOMICAL ASPECTS OF $\mu$ GEN AND C- $\mu$ GRID SYSTEM

\begin{tabular}{|l|l|c|c|}
\hline Aspect & Parameters & $\mu$ Gen System & $\begin{array}{c}\text { Community } \\
\mu \text { G System }\end{array}$ \\
\cline { 3 - 4 } & & $\begin{array}{c}50 \text { Houses } \\
(50 \text { unit })\end{array}$ & $\begin{array}{c}1 \text { Microgrid } \\
(1 \text { unit }=50 \\
\text { houses })\end{array}$ \\
\hline Technical & Wind Turbine & $6 \mathrm{~kW} /$ unit & $\begin{array}{c}6^{*} 50=300 \\
\mathrm{~kW}\end{array}$ \\
\cline { 2 - 4 } & Converter & $6 \mathrm{~kW} /$ unit & $300 \mathrm{~kW}$ \\
\cline { 2 - 4 } Economical & $\begin{array}{l}\text { Initial } \\
\text { investment }\end{array}$ & $€ 12000$ & $€ 600000$ \\
\cline { 2 - 4 } & $\begin{array}{l}\text { Total system } \\
\text { cost }\end{array}$ & $€ 14630$ & $€ 690000$ \\
\cline { 2 - 4 } & $\begin{array}{l}\text { Cost of } \\
\text { energy }\end{array}$ & $€ 0.10$ & $€ 0.09$ \\
\hline
\end{tabular}

\section{CONCLUSION}

In this paper, techno-economic analysis along with environmental and social aspects for $\mu \mathrm{Gen}$ and $\mathrm{C}-\mu \mathrm{Grid}$ systems has been discussed. A community based grid connected $\mu$ Grid system has been proposed. The advantages of the proposed system have also been discussed. Results show that without changing the government incentive/REFIT policy, community users can convert their $\mu$ Gen system towards the development of $\mathrm{C}$ - $\mu$ Grid system which can help to make their renewable energy based electricity system sustainable. Depending on the scenario, if some modification is done in the present policy (such as VAT exemption, increasing the electricity export rate or providing incentives for GHG reduction), it could make the system more viable. The analysis can set out some grounds for policy change to make the $\mathrm{C}-\mu \mathrm{Grid}$ more lucrative.

\section{REFERENCE}

[1] RH Lasseter, Paigi Paolo. Microgrid: a conceptual solution. IEEE APECS, Vol -6 (1), 2004, pp. 4285-4290.

[2] RH Lasseter. Microgrids. IEEE PES Trans and Dist Conference, Vol: 1, 2002, pp. 305-308.

[3] Project microgrids website, http://microgrids.power.ece.ntua.gr

[4] D. Pudjianto. G. Strbac ., etal. , Investigation of Regulatory, Commercial, Economic and Environmental issues in microgrids. International conference on future power systems, 2005

[5] L. Mariam, M Basu and M F Conlon, A review of existing microgrid architectures, International Conference on Sustainable Energy and Environmental Protection, 2012, Ireland

[6] F O'Rourke, F Boyle, A Reynolds, Renewable energy resources and technologies applicable to Ireland. Renewable and Sustainable Energy Reviews 2009, 13(8) pp. 1975-84.

[7] E Dennehy, M Howley, Dr. Brian Ó Gallachóir and Mary Holland, Renewable energy in Ireland 2012, Sustainable Energy Authority Ireland.

[8] Li Zhe, F Boyel , A Reynolds , Domestic application of micro wind turbines in Ireland: Investigation of their economic viability. Renewable Energy 41 (2012) 64-74

[9] A Status report on micro-generation in Ireland. http://www.seai.ie/Renewables/Microgeneration/Status_report_on_Mic rogeneration in Ireland.pdf

[10] P.M Costa., A Manuel., Matos, J.A Pecas Lopas., A regulatory framework for Micro-generation and microgrids. IEEE Con. Publication 2007 ( $633-638$ )

[11] Z Liu., F Wen., G Ledwich., Potential benefits of distributed generators to power systems, IEEE Explorer, 2011

[12] N.D Hatziargyrious., A. G Anastasiadis., J Vasiljevska., A G. Tsikalakis. Quantification of Economic, Environmental and Operational Benefits of Microgrids, IEEE Bucharest Power Tech. Conference, 2009 (1-8)

[13] Transmission Reliability Multi-Year Program, U.S. Department of Energy; May 2001. www.electricity.doe.gov./documents/tr_myp.pdf

[14] G Johnson, Onsite Power Generation: A Reference Book, Electrical Generation Systems Association, 1993.

[15] C David, O Juan, H Julie, C Daniel, M Richard, Novel Integrated Energy Systems and Control Methods with Economic Analysis for Integrated Community Based Energy System, Power Engineering Society General Meeting, IEEE, pp 1-6, 2007,

[16] AA Hamad, MA Alsaad, A software application for energy flow simulation for grid connected photovoltaic system. Energy conversion and management 51 (8), pp 1684-9, 2010

[17] Monthly wind speed data, Met Éireann; 2012

[18] Standard load profiles, 2011, Retail Market Design Service; 2009

[19] Power Distribution Planning, IEEE Course 92 EHO 361-6-PWR.

[20] Electric Ireland, ESB; https://www.electricireland.ie/ei/home/index.jsp 